\title{
Therapeutic Targeting of Cancer Cell Metabolism: Role of Metabolic Enzymes, Oncogenes and Tumor Suppressor Genes
}

Rabiya Majeed”, Abid Hamid”*, Yasrib Qurishi, Asif Khurshid Qazi, Aashiq Hussain, Mudassier Ahmed, Rauf Ahmad Najar, Javeed Ahmad Bhat, Shashank Kumar Singh and Ajit Kumar Saxena

Cancer Pharmacology Division, CSIR-Indian Institute of Integrative Medicine, Jammu 180001, India

"Equally Contributed

\begin{abstract}
Cancer cells compared to their normal counterparts reveal different metabolic needs and this differential requirement of metabolic intermediates and their subsequent consequences require an elaborate understanding of cancer cell metabolism and increased energy production in these cells. Nevertheless these metabolic differences have provided opportunities for developing novel therapeutic approaches for the cancer diagnosis and treatment. In addition enhanced proliferative capacities of tumor cells associated with aberrations of many signal transduction pathways resulting from genetic or epigenetic alterations has made it possible to develop countless targeted therapeutics for several types of malignancies. However at present most of our understanding about the dysregulated cancer cell metabolism is at physiological stages. With advancement in technology development, we may eventually be able to differentiate the metabolic differences between normal cells and cancerous at the single-tumor level that may influence the development of personalized cancer medicine. In this review, the focal point will be the recent developments in understanding the crucial role of metabolic enzymes, oncogenes and tumor suppressor genes in progression of cancer and their targeting to establish the most appropriate therapeutic strategies for better clinical outcome.
\end{abstract}

Keywords: Tumorigenesis; Glycolysis; Hexokinase; Hypoxia; Glutaminolysis; Oncogenes; Cancer therapy

\section{Introduction}

The metabolic response in mammalian cells requires a coordination of cellular activities that include cell proliferation with nutrient availability, regulation of energy homeostasis and hormonal and stress signaling. Cancer cells require unrestricted energy generation from ATP for their uncontrolled proliferation. Over the last few decades, there are accumulating evidences about the metabolic reorganization during cancer development which has been obtained from studies on various tumor types. The involvement of various metabolic enzymes and oncogenic proteins to cancer progression widen beyond the control of cell growth and division, and these may be responsible for the metabolic alterations associated to the pathogenesis of human cancers. It is well acknowledged that accessibility of nutrient enables nucleic acid, protein and lipid biosynthesis which helps to promote cell proliferation that is again associated with increased glycolytic flux and decreased oxidative metabolism. This transition to glycolysis for energy production provides several advantages to the tumor including adaptation to a low oxygen environment and the acidification of the surrounding microenvironment, which promotes tumor invasion and suppresses immune surveillance and the most important it provides necessary precursors for other biochemical pathways [1]. In contrast, lack of nutrient availability triggers a metabolic switch that leads to hyper activation of energy producing pathways, such as oxidative phosphorylation that restrict cell proliferation. In non-proliferating cells catabolic system is predominantly used to fulfill the energy requirements which use the mitochondrial oxidative phosphorylation along with oxidation of macromolecules to accomplish the energy needs. However, in highly proliferating tissues with high glycolytic flux, biosynthesis of macromolecules and lactate production leads to cell cycle progression, leading to a shift toward an anabolic metabolism [2]. Therefore metabolism and cell proliferation are under the common regulatory pathway to ensure a coordinated cellular response. Several pathophysiological conditions are associated with flux to a glycolytic metabolism and now it is an established fact that cancer progression and invasiveness is associated with major metabolic alterations. So the similar factors that trigger proliferation, e.g. oncogenes and some metabolic enzymes, the same factors coordinate the metabolic response of the cells to the external stimuli.

\section{Glycolysis in cancer, a crucial involvement of hexokinase}

Glucose is an essential energy source which helps to sustain life and it is also a source of carbon for cellular building blocks. It is therefore obvious that breakdown of glucose primarily through glycolysis is elevated in many human malignancies, particularly those with the most rapid growth rates. The glycolytic phenotype associated with these cells involves glucose phosphorylation, which entraps the glucose molecule within the cells for the tumor utility and involves the enzyme Hexokinase (HK-II) which is the first enzymatic step of glucose phosphorylation. The expression, regulation and localization of these specific isozymes of Hexokinase (HK) are regulated in such a way that is destructive to the host but highly advantageous to the tumor. It is because of this fact that the key isozyme i.e. Hexokinase II (HK-II) signify an ideal molecular targets for tumor destruction and inhibition of cancer cell proliferation. In general, hexokinase, has four isoforms denoted as HK I, II, III and IV (glucokinase). During the tumorogenic

*Corresponding author: Abid Hamid, Cancer Pharmacology Division, Indian Institute of Integrative Medicine, Council of Scientific and Industrial Research, Canal Road, Jammu 180001, India, Tel: +91-191-2569001, Extn: 352; Fax: +91191-2569333; E-mail: ahdar@iiim.ac.in

Received July 13, 2012; Accepted August 13, 2012; Published August 15, 2012

Citation: Majeed R, Hamid A, Qurishi Y, Qazi AK, Hussain A, et al. (2012) Therapeutic Targeting of Cancer Cell Metabolism: Role of Metabolic Enzymes, Oncogenes and Tumor Suppressor Genes. J Cancer Sci Ther 4: 281-291. doi:10.4172/1948-5956.1000156

Copyright: (C) 2012 Majeed R, et al. This is an open-access article distributed under the terms of the Creative Commons Attribution License, which permits unrestricted use, distribution, and reproduction in any medium, provided the original author and source are credited. 
response in tissues like liver and pancreas showed high expression of HK-II and to a lesser extent HK IV, this process, also lead to the HK IV expression silencing [3].

\section{Hexokinase II and its major partners: Role in cancer progression}

The maintenance of highly malignant phenotype by HK-II requires the association of four major protein partners (Figure 1). These include a plasma membrane Glucose Transporter (GLUT) present on the cell membrane that helps in the entry of glucose into the cancer cell, VoltageDependent Anion Channel (VDAC) which are pore-like proteins present on the outer mitochondrial membrane that binds HK-II; the inner mitochondrial membrane protein ATP synthase that synthesizes ATP, and adenine nucleotide translocator that transports the ATP to the VDAC-HK II complex. Due to the overall involvement of all these associated members which lead to the quick and efficient production of glucose-6-phosphate that serves as the precursor for glycolysis and also used for the biosynthesis of essential metabolic intermediates via the pentose phosphate pathway and the mitochondrial tricarboxylic acid cycle, which are exceptionally essential for the growth and proliferation of cancer cells. Thus, tumors have cleverly overproduced HK-II, and neutralized its capacity to be controlled thereby forcing the reaction between ATP and the incoming glucose to produce glucose-6phosphate at a high rate. This in turn forces glycolysis and biosynthetic metabolic pathways within tumors to function at an enhanced capacity thus providing optimal support for uncontrolled tumor proliferation. In addition, the lactic acid secreted by the tumor likely helps pave the way for this process either by suppressing attacks by the immune system, preparing normal cells for invasion, or both. In addition, cancer cells instruct the binding of $\mathrm{HK}$ II to VDAC thus inhibit

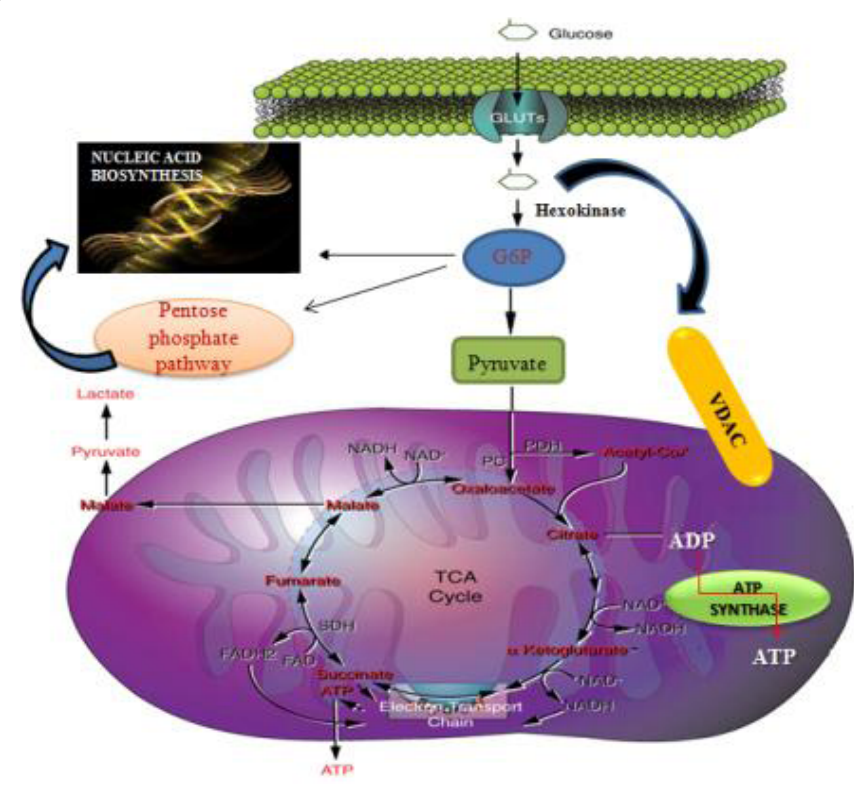

Figure 1: Role of hexokinase and its major partners. Delivery of glucose to hexokinase (HK) II within a malignant cell and metabolic fates of the glucose-6phosphate (G-6-P) formed. Glucose brought across the plasma membrane by glucose transporters is rapidly phosphorylated by HK. To maintain the highly glycolytic metabolic flux of such malignant cells, the product G-6-P is rapidly distributed across key metabolic routes. The primary routes are direct entry of the G-6-P into the pentose-phosphate shunt for biosynthesis of nucleic-acid precursors and conversion of the G-6-P via the glycolytic pathway to pyruvate and lactic acid. Here, whereas the lactic acid is transported out to provide an unfavorable environment for surrounding normal cells, some pyruvate is directed to to provide substrates for the tri-carboxylic acid (TCA) cycle. mitochondrial-induced cell death [4]. Studies carried over the last few decades have unraveled the biochemical interaction present between signal transduction and metabolic pathways in tumor cells which helps to promote malignant phenotype. It has now became an established fact that for the tumor immortality hexokinase-mitochondrial interactions are highly critical and that small-molecule metabolite analogs can cause tumors disruption via multiple metabolic target-point. With this a new class of potential anti-cancer therapeutics agents has appeared on the horizon. These are able to usurp the aberrant metabolic machinery of tumor cells to re-direct the metabolites which cause self-destruction of the tumor [5].

\section{Role of Phosphofructokinase-2 (PFK-2) as a key step for establishing cancer cell growth}

The rate of glycolytic flux is controlled at different levels and by different mechanisms substrate availability, enzyme concentrations, allosteric effectors and covalent modification on regulatory enzymes. In mammalian cells Phosphofructokinase-2 (PFK-2), has several isoforms encoded by four genes 6-phospho-2-kinase/fructose2, 6-biphosphatase (PFKFB1-4). These isoforms show differences in their tissue distribution and kinetic properties in response to allosteric effectors, hormonal, and growth factor signals. One of the critically modulated steps that is catalyzed by PFK-1, with fructose-2, 6-bisphosphate (Fru2,6-P2) being its most powerful allosteric activator. Fru-2,6-P2 relieves ATP inhibition and acts synergistically with AMP, and in addition it inhibits fructose 1,6-bisphosphatase. These properties confer to this metabolite a key role in the control of fructose 6-P/fructose 1,6P2 substrate pathway [6]. Moreover, PFK-2 is a bifunctional enzyme with activities of both kinase and phosphatase. This change the cellular level of fructose 2,6-bisphosphate (F2,6BP), which has got the most powerful potential to activate of PFK-1 in normal and tumor cells. The PFKFB3 gene encodes both ubiquitous PFK-2 and inducible PFK-2, former with the highest kinase/bisphosphatase ratio and later produced through the alternative splicing. It has been found that PFK2 FB3 gets over-expression by HIF- $1 \alpha$ which leads to an increase level of F2, 6BP in several tumor cells $[7,8]$. PFK-1 is commonly inactive in the cells in the absence of allosteric modulators, which may have a role in increased glycolysis in cancerous cells because of the fact that F2, 6BP which activate PFK-1 may readily overcome the citrate and ATP inhibition allowing glycolysis to proceed [9]. PFKFB4 isoform has also been found to regulate glycolysis in tumors mammary gland, and in these tumors levels of PFKFB4 has been found high. The over expression PFKFB3-4 genes are in various tumors, which get activated by oncogenes and/or, hypoxia indicates that they play an critical role in the glycolytic expression of cancer cells, due to which tumor cells get adapted for survival and proliferation and in their hypoxic microenvironment. Therefore glycotic suppression may act an efficient therapeutic strategy and, consequently the PFKFB3-4 inhibition could be one of the targets of such an approach.

\section{Pyruvate kinase (PK): involvement in cancer cell metabolism}

PK catalyses the rate-limiting, ATP-generating step of glycolysis in which Phosphoenolpyruvate (PEP) is converted to pyruvate. Multiple isoenzymes of PK exist in mammals: type l, which is found in the liver and kidneys; type $\mathrm{R}$, which is present in erythrocytes; type M1, which is found in tissues such as muscle and brain; and type M2, which is expressed in self-renewing cells such as adult stem cells and embryonic cells. The aerobic glycolysis ultimately leads to the generation of lactate from pyruvate rather than the transport of pyruvate to mitochondria where it could have gone under oxidation through mitochondrial tricarboxylic 
acid cycle. However, PK has its role above of this bifurcation leading to conversion of phosphoenolpyruvate to pyruvate [10]. Furthermore, it was discovered that although PKM1 could efficiently promote glycolysis and rapid energy generation, PKM2 is characteristically found in an inactive state and is ineffective in promoting glycolysis. PKM2 enzymatic activity, particularly when bound to pTyr residues, is substantially less than that of PKM1 [11]. PKM2 provides an advantage to cancer cells because, by slowing glycolysis, this isozyme allows carbohydrate metabolites to enter other subsidiary pathways, including the hexosamine pathway, uridine diphosphate (UDP)-glucose synthesis, glycerol synthesis and the pentose phosphate pathway (PPP), which generate macromolecule precursors, that are necessary to support cell proliferation, and reducing equivalents such as NADPH [12] (Figure 2). Subsequent studies have confirmed that PKM2 expression by lung cancer cells confers a tumorigenic advantage over cells expressing the PKM1 isoform [13]. Interestingly, the oncoprotein MYC has been found to promote preferential expression of PKM2 over PKM1 by modulating exon splicing. Myc upregulates the expression of heterogeneous nuclear ribonucleoproteins (hnRNPs) that bind exon 9 of the PK mRNA and leads to the preferential inclusion of exon 10 and thus to the predominant production of PKM2 [14]. By promoting PKM2 expression, MYC also promotes the production of NADPH in order to match the increased ATP production to sustain the additional needs required for high proliferation. Moreover, the increased PKM2 expression has been documented in patient samples of various cancer types, leading to the assumption that PKM2 may act as a useful biomarker for the early detection of tumors [15]. The PKM2 has been identified as a tumor specific enzyme whose activity is regulated by pTyr binding and it is also shown to be important for the aerobic glycolytic phenotype. By having still better understanding that how PKM2 works, how its expression is regulated, which phosphorylated tyrosine protein are necessary for PKM2 regulation in cancerous cells and how it is going to affect the fate of pyruvate could provide new directions for metabolism-based anticancer therapies.

\section{Association of pyruvate dehydrogenase kinase (PDK) for high energy demands in cancer}

Pyruvate represents a critical metabolic check point, as it can have two fates, either it can be converted to acetyl coenzyme A (AcCoA) by Pyruvate Dehydrogenase (PDH) for entry into the mitochondrial tricarboxylic acid (TCA) cycle or it can be transformed by Lactate Dehydrogenase (LDHA) to lactate. Pyruvate dehydrogenase kinase (PDK) is encoded by four genes and PDK1 is activated by hypoxia inducible factor-1 (HIF-1). PDK phosphorylates the catalytic domain of PDH and thus causes its inactivation. Due to the PDK1 activation, pyruvate is shunted away from the mitochondria, which in turn decreases flux through the TCA cycle, due to which release of NADH and FADH2 to the electron transport chain is reduced (Figure 3). This is a critical adaptive response shown under hypoxic conditions because Mouse Embryo Fibroblasts (MEFs) which are HIF-1 $\alpha$-null, PDK1 expression was not found to be affected by hypoxia and the cells die due to increased production of ROS which can be ameliorated by over expression of PDK1 [16]. It is also reported that inhibition of PDK1 or HIF-1 activity enhances $\mathrm{O}_{2}$ utilization by tumor cells and increases the efficacy of a hypoxia-specific cytotoxins [17]. Since the greater participation of PDK1 in Warburg effect and cancer, the development of effective PDK1 inhibitors may provide a influential approach for at least slowing down the growth of many forms of tumors.

\section{Glutaminase in cancer therapeutic strategy}

Another major event of changes in cancer metabolism that helps

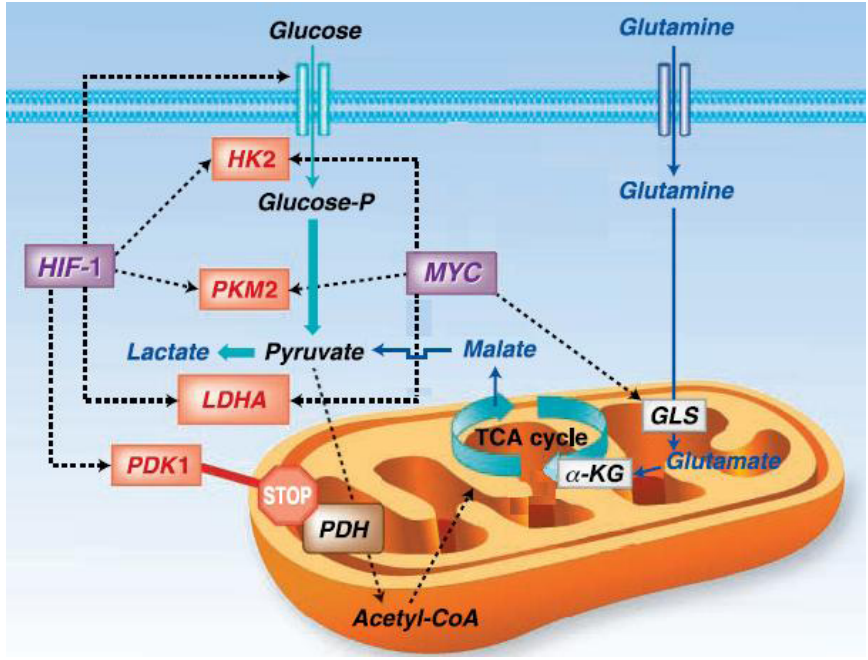

Figure 2: Myc and HIF-1 regulate glucose metabolism and stimulate the Warburg effect. Myc and HIF-1 are depicted to regulate (dotted lines) genes involved in glucose metabolism (glucose transporter Glut1, HK2, PKM2, LDHA, and PDK1), favoring the conversion of glucose to lactate (glycolysis). Myc is also depicted to stimulate glutamine metabolism through the regulation of glutaminase (GLS). Glutamine is shown converted to $\alpha$ - ketoglutarate ( $\alpha$ $\mathrm{KG}$ ) for catabolism through the TCA cycle to malate, which is transported into the cytoplasm and converted to pyruvate and then to lactate (glutaminolysis).

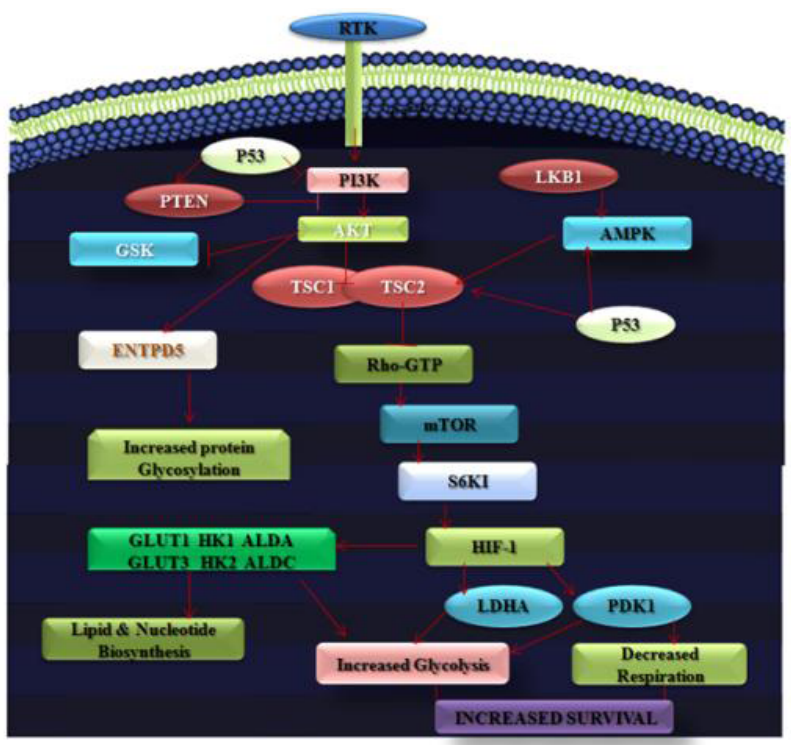

Figure 3: Oncogenic activation of PI3K, Akt, and mTOR pathways. Activation of receptor tyrosine kinase activates the PI3K, Akt, and mTOR pathways which leads to the activation of HIF which in turn activates LADH and PDK1 culminating in increased glycolysis and decreased respiration. HIF also activates GLUT 1 and 3, HK I and II ALDA and ALDAC which help in lipid and nucleotide biosynthesis all amplifying the tumor phenotype. p53 reverses this effect by regulating the transcription of three genes, PTEN, TSC2, and AMPK, which then all negatively regulate Akt kinase and mTOR, leading to a decrease in cell growth and a reversal of the cancer phenotype.

to accommodate the alterations in the glycolytic pathway and to sustain the malignant phenotypes, results in a shift to increased rates of glutamine metabolism. This occurs through the accelerated hydrolysis of glutamine to glutamate, as catalyzed by mitochondrial glutaminase, which is located in the inner mitochondrial compartment. Unlike glutaminase1, glutaminase 2 helps in the conversion of glutamine to 
glutamate and the successive renovation of glutamate to $a$-ketoglutarate is catalyzed by glutamate dehydrogenase. $\alpha$-ketoglutarate thus increasing the rate of TCA cycle and oxidative phosphorylation [18] (Figure 2). Moreover the enhanced production of a-ketoglutarate that is the outcome of elevated glutamine metabolism helps to maintain the TCA cycle in tumor cells, particularly given the loss of the input from pyruvate that is generated via glycolysis in normal cells [19]. There is also recent evidence that some glutamine derived carbon can exit the TCA cycle as malate and serve as a substrate for malic enzyme, which produces NADPH. Studies have shown that in cancerous cells TCA cycle remains intact and it serves to replenish metabolic intermediates necessary for the production of NADPH for fatty acid synthesis, to provide the carbon source for the elevated requirements of nucleotide synthesis as well as for the production of asparagine and arginine, and to serve as a major anaplerotic source of oxaloacetate [20]. One factor that is known to have a major role in regulating glutaminolysis is $\mathrm{c}-\mathrm{Myc}$, further supporting the concept that $\mathrm{c}-\mathrm{Myc}$ promotes not only proliferation but also the production of accompanying macro molecules and antioxidants that are required for growth. C-Myc increases glutamine uptake by directly inducing the expression of the glutamine transporters SlC5A1 and SlC7A1 also known as CAT1. Furthermore, c-Myc indirectly increases the level of glutaminase 1 (Gls1), the first enzyme of glutaminolysis, by repressing the expression of microRNA-23A and microRNA-23B, which inhibit GLS1 [21]. The fact that inhibiting the activation of glutaminase in transformed/ cancer cells with the small molecules has specific effects on the growth, migration and invasive activity of these cells, without affecting the growth or morphology of their non-transformed cellular counterparts, offers exciting new possibilities for therapeutic intervention. Consequently, a number of therapeutic strategies have been directed at inhibiting receptor activation and function, both through the use of inhibitors and monoclonal antibodies. Some of these strategies have shown some promise, although many of these cancers become resistant to such treatments, and there remains a need for the identification of additional druggable targets that will permit multi-pronged strategies for therapeutic intervention against a number of human malignancies [22,23] (Table 1).

\section{AMP-activated protein kinase and cancer}

AMP-activated protein kinase (AMPK) is a crucial energy status sensor enzyme and has an essential pleiotropic character in cellular responses to metabolic stress. The AMPK pathway couples energy status to growth signals and opposes the effects of AKT1 thus functions as a potent inhibitor of mTOR. During periods where cells suffer from energetic stress, AMPK becomes activated in response to enhanced AMP/ATP ratio, and is responsible for shifting cells to an oxidative metabolic phenotype and inhibiting cell proliferation [24]. For survival, tumor cells must overcome this checkpoint in order to proliferate in response to activated growth signalling pathways, even in non ideal microenvironment. Several oncogenic mutations and signaling pathways can suppress AMPK signaling which uncouples fuel signals from growth signals, allowing tumor cells to divide under abnormal nutrient conditions. This uncoupling permits tumor cells to respond to inappropriate growth signalling pathways that are activated by oncogenes and the loss of tumor suppressors [25]. The loss of AMPK signalling allows the activation of MTOR and HIF1, and therefore might also support the shift towards glycolytic metabolism. Clinically, there is currently considerable interest in evaluating whether AMPK agonists can be used to re-couple fuel and growth signals in tumor cells and to shut down cell growth.

\begin{tabular}{|c|c|c|}
\hline $\begin{array}{l}\text { Therapeutic } \\
\text { approach }\end{array}$ & Metabolic target & Agent \\
\hline $\begin{array}{l}\text { Inhibition of } \\
\text { glycolysis }\end{array}$ & $\begin{array}{l}\text { Hexokinase } \\
\text { Hexokinase VDAC complex } \\
\text { Lactate dehydrogenase } \\
\text { Pyruvate dehydrogenase } \\
\text { kinase (PDK) } \\
\text { Phosphofructokinase } \\
\text { Pyruvate kinase (PK) }\end{array}$ & $\begin{array}{l}\text { 2-Deoxyglycose, } \\
\text { 3-bromopyruvate, lonidamine. } \\
\text { Methyl jasmonate } \\
\text { Oxamate a-cyano-4-hydroxy } \\
\text { cinnamic acid } \\
\text { Dichloroacetate } \\
\text { (3-(3-pyridinyl)-1-(4-pyridinyl)-2- } \\
\text { propen-1-one } \\
\text { CAP-232/TLN-232 }\end{array}$ \\
\hline $\begin{array}{l}\text { Glutamine } \\
\text { metabolism }\end{array}$ & $\begin{array}{l}\text { Glutamine (analogs) } \\
\text { Glutamine }\end{array}$ & $\begin{array}{l}\text { 6-Diazo-5-oxo-L-norleucine, } \\
\text { azaserine } \\
\text { L-Asparginine, Phenylbutyrate }\end{array}$ \\
\hline $\begin{array}{l}\text { PI3K/AKT/ } \\
\text { mTOR }\end{array}$ & $\begin{array}{l}\text { PI3K } \\
\text { mTOR } \\
\text { AKT }\end{array}$ & $\begin{array}{l}\text { LY294002, Wortmannin, } \\
\text { GDC-0941, PX-866, CAL-101, } \\
\text { BEZ235 and XL765. } \\
\text { Temsirolimus (CCI779) and } \\
\text { Everolimus (RAD001) } \\
\text { Perifosine, PIAs Triciribine } \\
\text { (API-2) }\end{array}$ \\
\hline
\end{tabular}

Table 1: Therapeutic strategies to target metabolic enzymes and relevant agents.

\section{Tumor suppressor genes and oncogenes: control over the metabolic alterations}

A decreased oxidative phosphorylation, increased glucose consumption and subsequent lactate production are the remarkable features of oncogenic activation [26]. Over the last decade, evidence has accumulated that the oncogenes myc, AKT, nuclear factor $\mathrm{kB}$ (NF-kB) and the tyrosine kinase receptors (insulin-like growth factor 1, epidermal growth factor, EGF; IGF-1; Her-2; etc.), which turn on phosphatidylinositol 3-kinases (PI3Ks), mammalian target of rapamycin (mTOR) pathway and the Ras, RAF-Mitogen-Activated Protein Kinase (MAP kinase) (Figure 4) along with hypoxia induced factor (HIF), can activate the transcription of numerous genes that encode the proteins that mediate the various metabolic pathways [27]. Myc and HIF-1 transcription factors enhances the rate of transcription of some of the GLUT transporters and hexokinase 2, increasing both glucose uptake and its retention in the cell [28]. Similarly, Warburg effect is initiated by the loss of tumor suppressor p53 functions. The p53 protein has the function that it suppresses the transcription of the GLUT 1 and 4 transporters. GLUT levels have been found to be in increased levels in tumor cells than in normal counterparts [29].

\section{Involvement of Ras and Myc in cancer specific pathways}

Mutations and altered expression in Ras or Myc oncogenes have been coupled to the initiation of most of human malignancies. Ras or Myc oncogenes are regarded as the mediators of the increased metabolic and proliferative response of tumor cells [30]. c-Myc promotes glycolysis through upregulation of glycolytic molecules including GLUT1, HK-II, Phosphofructokinase (PFK), enolase, and LDH. c-Myc and Ras oncogenes apart from their role in the cell cycle and proliferation, they also participate in the regulation of tumor cell metabolism (Figure 2). Lactate dehydrogenase A (LDH-A) regulated by $\mathrm{c}-\mathrm{Myc}$, leads to the conversion of pyruvate to lactate and contributes to the Warburg effect [31,32]. Furthermore, c-Myc also has an essential role in regulation of mitochondrial functioning and its biogenesis that has been supported by the reports which say that large number of genes which are involved with the genesis of the mitochondria and its functions are over expressed among transcriptional targets of c-Myc. Interestingly, Ras-mediated cell alteration is associated with enhanced 


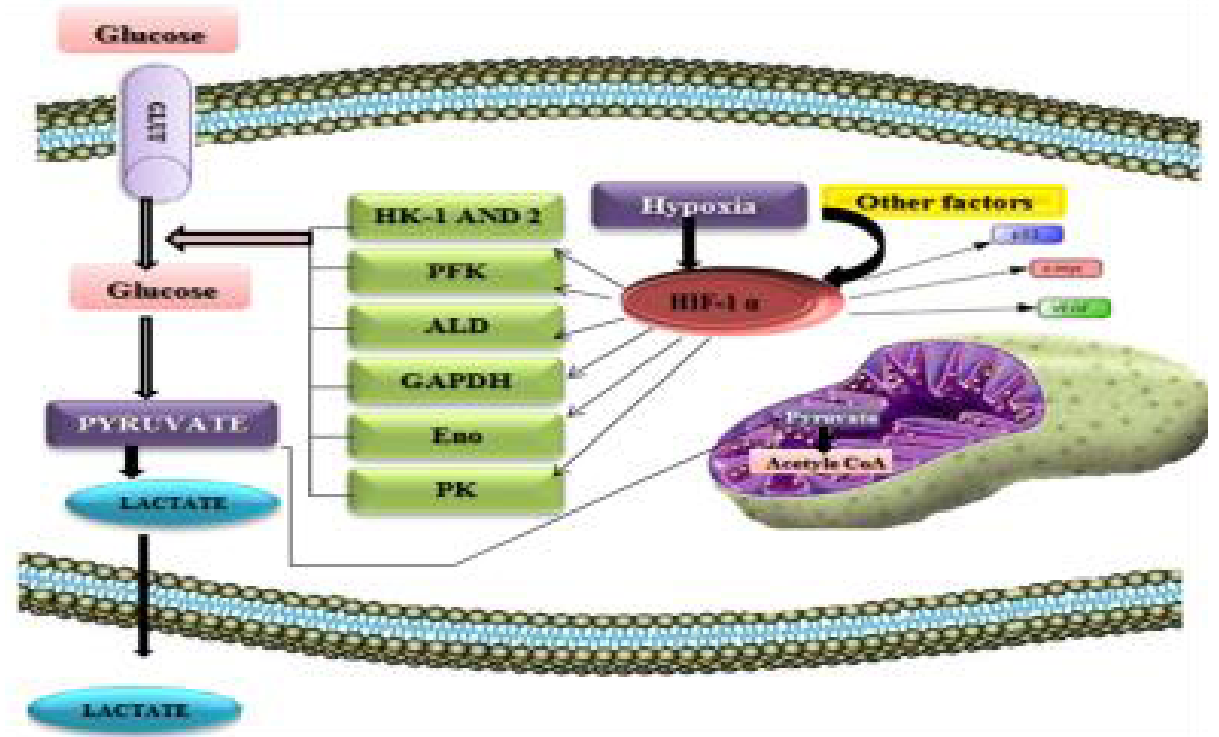

Figure 4: Role of HIF-1 $\alpha$. HIF is a heterodimer consisting of an unstable $\alpha$-subunit and a $\beta$-subunit. In the absence of oxygen and other factors HIF-1 $\alpha$ is activate which leads to the activation of all the glycolytic enzymes producing lactate from pyruvate which is transported out of the cell adding to the malignant phenotype.

variation in cellular metabolism, which includes increased glucose uptake and glycolysis, dysfunction of mitochondrial and increased production of lactic acid. This is because of the enhanced expression of genes of the aerobic glycolytic pathway and lactate dehydrogenase $[33,34]$. It is important to note that c-Myc also plays a major role in promoting glutamine use in cancer cells through upregulating the expression of glutamine transporters SLC5A1and SLC7A1 and enhancing the expression of GLS1 by repressing the expression of miR-23A and miR-23B thus releasing the suppressive effect of these miRNAs on GLS1 expression [21]. Similar to other oncogenes, Ras is also associated with the regulation of de novo lipid synthesis, primarily through regulation of transcription factor Sterol Regulatory ElementBinding Protein (SREBP) mediated by the MAPK pathway $[35,36]$. Thus understanding that importance of these oncogenes which directly regulate multiple metabolic pathways suggests that new therapeutic opportunities do exist, particularly in altered cancer metabolism.

\section{The oncogenic pathway involving PI3K and AKT}

The phosphatidylinositol-3 kinase (PI3K) pathway is one of the most commonly altered signalling pathways in human cancers. This pathway is activated by mutations in tumor suppressor genes, such as PTEN, mutations in the components of the PI3K complex itself or by aberrant signaling from receptor tyrosine kinases [37]. Once activated, the PI3K pathway not only provides strong growth and survival signals to tumor cells but is also shown to have intense effects on cellular metabolism. So the integration of growth and proliferation signals with alterations to central metabolism is crucial for the oncogenic effects of this signalling pathway [38]. The best-studied effector downstream of PI3K is Aktl (also known as PKB). The serine threonine kinase Akt (or PKB) plays a dual role in regulating both cell proliferation and metabolism. The most versatile factor associated with the controls of the metabolic response to both oncogenic and metabolic stimuli are the Ras and insulin signaling respectively. Akt execution in metabolism covers from protein and fatty acid synthesis to glucose homeostasis [39]. Since Akt is known to be a major mediator involved in the uptake of glucose and its utilization and is therefore not surprising that Akt is associated with high glycotic activity in tumor cells [40]. Moreover, Akt activation through growth factor result in enhanced expression and membrane distribution of the GLUT1 [41], mitochondrial association of hexokinase I and II and stimulation of Phosphofructokinase (PFK) activity, thereby increasing glycolysis. Akt maintains the association of hexokinase with mitochondria and that this association may somehow prevent the release of cytochrome $\mathrm{c}$ and apoptosis. Ectopic HKI or HKII expression mimics the ability of growth factors and Akt to inhibit apoptosis. Growth factor stimulation of mitochondrial hexokinase association is abrogated in Akt-deficient cells, an effect that is mimicked by pharmacologic inhibition of PI3K [42]. Also Akt and mitochondrial hexokinase requires glucose to inhibit apoptosis and cytochrome c release. Glucose deprivation, which impairs the ability of Akt to both maintain mitochondrial integrity and inhibit apoptosis, has also been associated with reduced mitochondrial hexokinase association. Moreover targeted disruption of hexokinase-mitochondria interaction impairs the antiapoptotic and mitochondrial integrity-promoting functions of growth factors and Akt. There is also evidence to suggest that glucose metabolism is required for these effects. The short-term ability of the phosphorylatable glucose analog 2-deoxyglucose but not the non-phosphorylatable analog 5-thioglucose to substitute for glucose in this regard suggests that glucose phosphorylation, by hexokinase activity, is specifically required which is directly verified using a catalytically inactive mutant of hexokinase. The fact that 2-deoxy-glucose that can be phosphorylated but not metabolized further, has made it useful to image cancers for the first time in human patients. In this technique the compound was labeled with the positron emitter ${ }^{18} \mathrm{~F}\left({ }^{18} \mathrm{FDG}\right)$ [43]. In addition, Akt plays important role in initiating de novo Fatty Acid (FA) synthesis. Akt Activation is also associated with increased expression of gene and thus their respective enzymes involved in cholesterol or fatty acid biosynthesis, like ATP citrate lyase (ACL), HMG-CoA reductase, Stearoyl-Coa Desaturase (SCD) and Fatty Acid Synthase (FAS). Transcription of all of these enzymes with regard to Akt require the activity of the Sterol Regulatory Element-Binding Protein (SREBP) family of transcription factors, whose synthesis and nuclear accumulation are 
also induced by activation of Akt [44]. Another important observation is that Akt also directly phosphorylates and activates the ATP-citrate lyase (ACL) [45] which is an important enzyme integrating lipid and glucose metabolism. AKT1 also activates Ectonucleoside Triphosphate Diphosphohydrolase 5 (ENTPD5), an enzyme that supports increased glycosylation of protein in the endoplasmic reticulum and indirectly increases glycolysis by creating an ATP hydrolysis cycle [46]. Furthermore Akt phosphorylates GSK3 isoforms on a highly conserved N-terminal regulatory site (GSK3a-S21, GSK3 $\beta$-S9), leading to its inactivation [47]. Finally, AKT1 strongly stimulates signaling through the kinase i.e. mTOR by phosphorylating and inhibiting its negative regulator tuberous sclerosis 2 (TSC2; also known as tuberin) [48]. mTOR functions as a key metabolic integration point, coupling growth signals to nutrient availability. Activated mTOR stimulates protein and lipid biosynthesis besides cell growth in response to sufficient nutrient and energy conditions and is often constitutively activated during tumorigenesis [49]. At the molecular level, mTOr directly stimulates mRNA translation and ribosome biogenesis and indirectly causes other metabolic changes by activating transcription factors such as Hypoxia-Inducible Factor 1 (HIF1) even under normoxic conditions. The subsequent HIF1-dependent metabolic changes are a major determinant of the glycolytic phenotype downstream of PI3K, Akt1 and mTOR (Figure 3). Akt therefore participates in the first committed step in channeling metabolites derived from glucose towards a lipid biosynthetic fate. Explaining the various components of the pathway that leads to the initiation of the tumor is critical for developing an intervention strategy. Tumors become addicted to these initiating events which lead to the avenues of growth. Thus, drugs that target the underlying perturbation will be more effective with fewer side effects than drugs that act as general growth suppressors.

\section{Function of hypoxia inducible factor (HIF) during carcinogenesis}

HIF a transcription factor that is stabilized in response to hypoxia besides having its role in the oncogenic activation of aerobic glycolysis, also have considerable effect in the conversion of glucose to lactate [50]. It is believed that the driving mechanism for the increased glycolysis in tumor cells is because of the enhanced transcription and translation of glycotic genes via the hypoxia inducible factor 1 (HIF1). HIF-1 is consisted of two subunits, HIF- $1 \alpha$ and HIF- $1 \beta$. Under aerobic conditions HIF-1 $\alpha$ is degraded by von Hippel Lindau protein (VHL), a tumor suppressor which initiates its degradation through Proteosome mediated pathway. However under anaerobiosis, HIF-1a is highly stable due to the mutations in the VHL protein due to which this tumor suppressor gets inactivated as has been found in most of the aggressive tumors (Figure 4) [51]. In turn, HIF-1 aggressiveness promotes the expression of PFK-1, phosphofructokinase type 2 (PFK2), HK, Glyceraldehyde-3-Phosphate Dehydrogenase (GAPDH) aldolase (ALD), enolase, pyruvate kinase, phosphoglycerate kinase, and LDH $[52,53]$. In addition, HIF stimulates angiogenesis by upregulating among others several factors, the Vascular Endothelial Growth Factor (VEGF). Furthermore the levels of oxygen within a tumor differ both temporally and spatially which result in fluctuating levels of oxygen which result in constitutive unregulated glycolysis. There are exceptions where the tumor with mutated von Hippel-Lindau protein (VHL), HIF is still coupled to oxygen levels, which shows the heterogenous expression of within the tumor microenvironment. This suggested that the Warburg effect cannot be explained solely by upregulation of HIF. Other molecular mechanisms such as the metabolic changes induced by oncogene activation and tumor suppressor loss are also likely to be involved.

\section{Control over the oncogenic pathway: Role of tumor suppressor genes}

The p53 protein induces the transcription of the TP53-induced glycolysis and regulator of apoptosis gene (TIGAR), which leads to decrease in glycolysis due to lowering in the intracellular levels of fructose 2,6 bisphosphatase (FBPase) hence diverging glucose to the PPP [54]. TIGAR also has functional similarities to the bisphosphate domain of PFK-2/FBPase-2 hence regulating ROS levels, glycolysis, and apoptosis. The p53 activation also leads to enhanced ubiqutination of phosphoglycerol mutase, which lowers the activity of this glycolytic enzyme. It has been also found that p53 enhances the utilization of TCA cycle and oxidative phosphorylation. Moreover, the p53 protein has a role in the transcription of the gene for the Synthesis of Cytochrome C Oxidase 2 (SCO2), which, along with Synthesis of Cytochrome C Oxidase 1 (SCO1), assembles into oxidative phosphorylation complexes [55]. In this context, cells with mutant p53 have compromised oxidative phosphorylation chains. p53 also has a role in promoting the synthesis number of proteins that reduce the high ROS load in cells. p53 also regulates the expression of p21 gene which synthesizes p21 protein which binds to Nrf2 transcription factor and thus stabilizes it. This transcription factor regulates a complex set of responses to high ROS load and altered redox potentials. Activated p53 also inhibits of the PI3K/Akt/mTOR pathways. Here p53 regulates the transcription of IGF binding protein-3 (IGF-1BP-3), tuberous sclerosis protein 2 (TSC-2), PTEN and the beta subunit of AMP-activated protein kinase (AMPK), which all negatively regulates AKT kinase and mTOR. Furthermore sestrins 1 and 2, which are p53-regulated genes, stimulate AMPK activity. In some instances, the net result leads to a p53-directed apoptosis and the activation of autophagy [56]. PTEN is a phosphatase of phosphatidyl inositol tri-phosphate (PIP-3) and therefore mediated the inactivation of the PI3K/Akt pathway. Loss of PTEN function or its mutations not only leads to cancer progression, but also exhibits striking effects on metabolism homeostasis [57]. This is of great importance for cancer cells as they are solly dependent on increased glycolytic flux. PTEN negatively regulator insulin pathway, and therefore has negative effects on lipogenesis, another hallmark of cancer cells [58]. Paradoxically phosphor retinoblastoma ( $\mathrm{pRb}$ ) is a major modulator of oxidative metabolism. Retinoblastoma $(\mathrm{Rb})$ specific deletion in adipose tissue results in increased mitochondrial activity and reversal from anabolic white adipose tissue to catabolic oxidative brown adipose tissue. In this particular situation RB would facilitate a cancer-type metabolism. All of these activities shut down cell growth, lower HIF levels, decrease the Warburg effect, and thus reverse the cancer phenotype [59]. Therefore mutations in oncogenes and tumor suppressor genes which cause alterations to multiple intracellular signalling pathways that affect tumor cell metabolism and reengineer it to allow enhanced survival and growth. The unique biochemical microenvironment further influences the metabolic phenotype of tumor cells, and thus affects tumor progression, response to therapy and patient outcome. These metabolic adaptations must balance the three crucial requirements of tumor cells: increased energy production, sufficient macromolecular biosynthesis and maintenance of redox balance. Only by thoroughly dissecting these processes will we discover the Achilles heels of tumor metabolic pathways and be able to translate this knowledge to the development and implementation of novel classes of therapeutics. The ultimate goal is to design treatment 
strategies that slow tumor progression, improve the response to therapy and result in a positive clinical outcome.

\section{Targeting the metabolic enzymes during cancer development: Future therapeutic strategies}

A significant difference between cancer cells and their normal counter parts resides in the oncogenic activation of deregulated biomass accumulation independent of nutrient availability to the cancer cells. Cancer cells are used to the continued supply of bioenergetic and anabolic substrates necessary for their continued growth and proliferation due to activation of oncogenes or loss of tumor suppressors. When the bioenergetic supply becomes lesser than the bioenergetic demands, cancer cells undergo autophagy and finally bioenergetic cell death. Keeping the idea in view, key metabolic enzymes and regulators necessary for bioenergetic supply could be used as therapeutic targets with sufficient therapeutic windows sparing normal and healthy cells [60]. HK- II which is a mitochondrial associated enzyme and a transcriptional target of HIF-1 and Myc has been deemed a therapeutic target for many years. Once glucose is transported into the cell, it is phosphorylated by HK-II and is retained intracellularly by the acquisition of negative charges. Glucose-6phosphate is then converted to fructose-6-phosphate by glucose phosphate isomerase, which is also known as autocrine motility factor. Over several years, 3-bromopyruvate was consideration to target HK-II, although the proteomic analyses suggest that 3-bromopyruvate targets glyceraldehydes 3-phosphate dehydrogenase (GAPDH). Although, 3-bromopyruvate show some lack of specificity but have significant anti-cancer outcome in vivo. More specific inhibitors to HK-II are not yet available to determine whether specific targeting of HK-II is feasible and tolerable [61]. Similarly, the plant derived methyl jasmonate or the HK-II amino terminus derived peptide TATHK can also disrupt the association between the voltage dependent anion channel (VDAC) and hexokinase, a phenomenon observed more in cancer cells compared to normal cells. Lonidamine, a derivative of indazole3carboxylic acid, was shown to inhibit tumor growth through inhibition of HK-II, depletion of ATP, reduction of oxygen consumption, and lactate production [62]. Phosphofructo-1-kinase (PFK), which acts downstream of HK-II in glycolysis, converts fructose-6-phosphate to fructose-1,6- bisphosphate. PFK is allosterically regulated by ATP and fructose-2,6-bisphosphate (F2,6-BP). ATP being a potent inhibitor and fructose-2,6-bisphosphate (F2,6-BP) a potent activator. A family of four enzymes, 6-phosphofructo-2-kinase/fructose-2,6-bisphosphatase (PFKFB 1-4) such that the elevated F2,6-BP level enhances glycolysis and diminished F2,6-BP level could decrease PFK activity and favor the shunting of glucose-6-phosphate into the pentose phosphate pathway (PPP). PFKFB3, a potent target of HIF-1 produces F2, and 6-BP favors glycolysis. A small molecule inhibitor of PFKFB3 (3-(3-pyridinyl)1-(4-pyridinyl)-2-propen-1-one (3PO) was documented to inhibit glycolysis in vitro and xenograft tumor growth in vivo [63]. The PFKFB family of enzymes being critical players of cancer metabolism would be of greater interest for targeted cancer therapy (Table 2).

Pyruvate Kinase (PK) converts phosphoenolpyruvate to pyruvate with the release of an ATP molecule, is a target gene of HIF-1 and Myc with two splice variant mRNAs. The splicing variant PKM2, which is favored by a Myc-induced splicing factor, has been linked to altered cancer metabolism for over a decade, but recent interest in this potential target was heightened by its rediscovery as a critical contributor to the Warburg effect. PKM2 itself does not contribute to the Warburg effect, rather another pathway for the generation of pyruvate from phosphoenol pyruvate has been proposed to account for the increased aerobic glycolysis as observed with PKM2 expression [64]. Given that activated PKM2 slows glycolysis, efforts are being made to explore the potential use of PKM2 inhibitors for therapeutic purposes [65] Lactate dehydrogenase A (LDHA) which is again a target gene of Myc and HIF-1, has been documented to be essential for human Burkitt lymphoma clonogenicity and also demonstrated to be essential for tumorigenesis by gene knockdown in three independent studies, after it [66,67]. A small-molecule inhibitor of LDHA (FX11; 3-dihydroxy-6methyl-7-(phenylmethyl)-4-propylnaphthalene-1-carboxylic acid) was shown to trigger oxidative stress in cancer cells similar to gene knockdown mediated by siRNA, resulting in necrotic cell death [68]. Reduced of LDHA activity along with elevation of NADH/NAD+ ratio was linked with an enhanced reactive oxygen species (ROS) generation and cell death. It is speculated that excess NADH could diminish upstream glycolytic flux, which requires recycled NAD+, and increase inappropriate respiratory complex I activity and ROS production, resulting in cell death that was partially rescued by the antioxidant $\mathrm{N}$-acetylcysteine. Because LDHA is important for the synthesis of lactate in the Warburg effect, its inhibition plays a central role in aerobic glycolysis. The Warburg effect is increased by HIF-1 and $\mathrm{Myc}$ as they lead to activation of pyruvate dehydrogenase kinase 1 (PDK1) which phosphorylates and inactivates pyruvate dehydrogenase (PDH). Inhibition of PDH lowers the conversion of pyruvate to acetyl-CoA, permitting more pyruvate to be converted to lactate. PDK1 appears pivotal for the regulation of redox balance through titrating pyruvate flux into the mitochondrion as a function of oxygen availability. When oxygen is low, continued pyruvate flux to acetyl-

\begin{tabular}{|c|c|c|c|c|}
\hline Enzyme & $\begin{array}{l}\text { Pathway } \\
\text { controlled }\end{array}$ & Gene involved & Isoform expressed in tumor cells & Isoform expressed in normal cells \\
\hline Hexokinase & Glycolysis & Hexokinase (HK) & Hexokinase II (HK II) & Hexokinase I, III, IV (HK I, III and IV) \\
\hline $\begin{array}{l}\text { Phosphofructokinase-2 } \\
\text { (PFK-2) }\end{array}$ & Glycolysis & $\begin{array}{l}\text { 6-phospho-2-kinase/fructose2, } \\
\text { 6-biphosphatase (PFKFB1-4) }\end{array}$ & $\begin{array}{l}\text { 6-phospho-2-kinase/fructose2, } \\
\text { 6-biphosphatase (PFKFB3 and } \\
\text { PFKFB4) }\end{array}$ & $\begin{array}{l}\text { 6-phospho-2-kinase/fructose2, } \\
\text { 6-biphosphatase (PFKFB1 and } \\
\text { PFKFB2) }\end{array}$ \\
\hline Pyruvate Kinase & Glycolysis & $\begin{array}{l}\text { Pyruvate Kinase M1 and M2 (PKM1 } \\
\text { and PKM2) }\end{array}$ & Pyruvate Kinase M2 (PKM2) & Pyruvate Kinase M1 (PKM1) \\
\hline $\begin{array}{l}\text { Pyruvate dehydrogenase } \\
\text { kinase (PDK) }\end{array}$ & $\begin{array}{l}\text { Between } \\
\text { Glycolysis and } \\
\text { TCA Cycle }\end{array}$ & $\begin{array}{l}\text { Pyruvate dehydrogenase kinase } \\
\text { (PDK 1-4) }\end{array}$ & $\begin{array}{l}\text { Pyruvate dehydrogenase kinase } \\
\text { (PDK)1 }\end{array}$ & $\begin{array}{l}\text { Pyruvate dehydrogenase kinase } \\
\text { (PDK2, PDK3 and PDK4) }\end{array}$ \\
\hline Glutaminase & $\begin{array}{l}\text { Glutamine } \\
\text { metabolism }\end{array}$ & Glutaminase 1 and Glutaminase 2 & Glutaminase 2 & Glutaminase 1 \\
\hline
\end{tabular}

Table 2: Metabolic enzymes, the pathway they regulate and their isoforms expression in normal and tumor cells. 
CoA triggers increased ROS production and decreased cell survival. In this regard, inhibition of PDK by dichloroacetate (DCA) that has been used clinically to manage congenital lactic acidosis appears to have an anti-tumor effect preclinically in select tumor models. It is also worth mentioning that while the Warburg effect is mediated by known critical enzymes in glucose metabolism, regulated by Myc and HIF-1, inhibition of PDK1 and LDHA results in redox stress and finally cell death. These observations suggest that inhibition of these enzymes affect glucose metabolism on one hand but also have profound effect on redox homeostasis on other hand. Also glucose-6-phosphate can be catabolized through the PPP to make NADPH and ribose, a key catabolite for reductive metabolism. Enzymes in the PPP, such as transketolase (TKT), have been suggested to be a therapeutic target and thiamine analogs have been proposed as transketolase inhibitors [69].

\section{Targeting glutamine in cancer metabolism}

The dependency of cancer cells on glutamine was not fully appreciated by Warburg some 80 years ago. It was documented that Myc regulates many steps in glutamine metabolism which suggest that key points in glutamine metabolism could be targeted in cancer cells. Since, Myc could post-transcriptionally increase glutaminase (GLS) levels which convert glutamine to glutamate that in turn is catabolized to $a$-ketoglutarate, finally entering in the TCA cycle. Large numbers of inhibitors were secreened for RhoGTPase mediated transformation, and finally a small molecule 968 was reported to inhibit transformation through inhibition of GLS [70]. Furthermore regulation of metabolism in cancer cells by isocitrate dehydrogenase (IDH) mutations has been frequently found in human gliomas and acute myelogenous leukemia, which is also exploitable for anticancer therapy [71]. Specifically, IDH1 and IDH 2 mutations result in a neo-enzyme activity that converts a-ketoglutarate to 2-hydroxyglutarate rather than the normal reaction of IDH resulting in the conversion of isocitrate to a-ketoglutarate [72]. Thus, it is conceivable that inhibitors of mutant IDH might be therapeutically useful if cancer cells with mutant IDH are dependent on the mutant enzyme for their cancer phenotype. The reprogramming of metabolism by mutant IDH, particularly through increased production of 2-hydroxyglutarate from glutamine, suggest that cancer cells with mutant IDHs are addicted to glutamine as a source for $\alpha$-ketoglutarate that is then converted to 2-hydroxyglutarate. The concept was tested by inhibition of glutaminase by siRNA-mediated knock-down and a small-molecule inhibitor (BPTES; bis-2-(5-phenylacetamido-1,2,4thiadiazol-2-yl) ethylsulfide) [73]. Both approaches caused a more significant delay in the growth of glioma cells engineered to inducibly express mutant IDH1 as compared to those expressing wild-type IDH1. This study suggests that reprogrammed metabolism in cancer cells can be targeted.

\section{Inhibition of PI3K/AKT/mTOR axis}

Targeting PI3K: Wortmannin and LY294002 are two well known, first generation PI3K inhibitors. LY294002 was the first synthetic drug like small molecule inhibitor to be capable of reversibly targeting PI3K family members at concentrations in the micromolar range. However, both wortmannin and IY294004 show little or no selectivity for individual PI3K isoforms and have considerable toxicity in animals [74,75]. Numerous PI3K inhibitor chemotypes, some of which show differential isoform selectivity, have been described [75,76]. A recent study [76] presented a comparison of isoform selectivity profiles among a collection of potent and structurally diverse PI3K inhibitors. The data underlined a crucial role for p110a in insulin signalling and also provided important insights for the development of isoforms selective
PI3K inhibitors. Subsequently, PI103, a p110a specific inhibitor, was shown to have a potent effect in blocking PI3K signalling in glioma cells through its ability to inhibit both p110a and mTOR [77]. The seemingly off target effects of PI103 on mTOR complexes opened a new avenue in the search for an effective cancer therapy strategy that uses a combined inhibition of mTOR and PI3K. Numerous PI3K targeted compounds are being introduced into clinical trials, many of which are dual PI3K-mTOR inhibitors. BEZ235 is an imidazoquinazoline derivative that inhibits multiple class I PI3K isoforms and mTOR kinase activity by binding to the ATP binding pocket [78]. The class I PI3K inhibitors Xl765 (which also targets mTOR) and XL147 are currently under Phase I clinical investigation for treatment of solid tumors. Both are derivatives of quinoxaline, as revealed by their recently disclosed structures [75]. GDC0941 is a derivative of PI103 that is active against all isoforms of class I PI3Ks in the nanomolar range. SF1126 is a covalent conjugate of LY294002 with an arg-gly-asp peptide, designed for increased solubility and enhanced delivery of the active drug to the tumor [79]. Numerous compounds that preferentially target selected isoforms of class I PI3Ks are also under development. For example, PX 866 targets p110a, p110 $\delta$ and p110 $\gamma$ with half maximal inhibitory concentration $\left(\mathrm{IC}_{50}\right)$ values in the low nanomolar range 70 , and $\mathrm{Cal} 101$ is a p110 $\gamma$ selective inhibitor (Supplementary Figure 1).

Targeting Akt: Akt is the most crucial proximal node downstream of the RTK-PI3K complex, and is therefore another attractive therapeutic target. Several AKT inhibitors have been developed, which can be grouped into various classes, including lipid based phosphatidylinositol analogues, ATP competitive inhibitors, and allosteric inhibitors. The most clinically advanced inhibitor, perifosine, is a lipid based phosphatidylinositol analogue that targets the pleckstrin homology domain of Akt, which prevents Akt from binding to PtdIns $(3,4,5) \mathrm{P} 3$ and undergoing membrane translocation [80]. Other AKT pleckstrin homology domain inhibitors, including PX316 [81] and phosphatidylinositol ether lipid analogues, have shown inhibitory effects on the growth of tumor cells that have high PI3K and AKT activity [82]. Most ATP competitive small molecule AKT inhibitors are non selective, targeting all three Akt isoforms. GSK690693 is an ATP competitive AKT kinase inhibitor, which targets all three Akt isoforms at low nanomolar concentrations and is active against additional kinases from the AGC (cyclic AmP dependent, cGmP dependent and protein kinase C) kinase family [83]. Xl418, a small molecule that inhibits Akt and S6K and has shown antineoplastic activity in preclinical studies, is in Phase I clinical trials in patients with advanced solid tumors.

Targeting mTOR: Although mTOR was only recently defined as a member of the PI3K pathway, it is the first node of the pathway to be targeted in the clinic. Rapamycin the prototypical mTOR inhibitor, is a bacterially derived natural product that was originally used as an antifungal agent [84]. It was subsequently found to have immunosuppressive [85] and, more recently, anti neoplastic properties. Rapamycin associates with its intracellular receptor, FK506 binding protein 12 (FKBP12), which then binds directly to mTORC1 and suppresses mTOR mediated phosphorylation of its downstream substrates, S6K and 4EBP1. Analogues of rapamycin, such as temsirolimus and everolimus have been developed as anti cancer drugs. These rapamycin analogues, sometimes referred to as rapalogues, inhibit mTOR through the same mechanism as does rapamycin, but have better pharmacological properties for clinical use in cancer. However, preliminary results with $\mathrm{mTOR}$ inhibitors in many other tumor types, including advanced breast cancer and glioma, indicated 
Citation: Majeed R, Hamid A, Qurishi Y, Qazi AK, Hussain A, et al. (2012) Therapeutic Targeting of Cancer Cell Metabolism: Role of Metabolic Enzymes, Oncogenes and Tumor Suppressor Genes. J Cancer Sci Ther 4: 281-291. doi:10.4172/1948-5956.1000156

a low response rate [86]. mTOR also presents a potential second target namely, its mTORC2 complex that functions as a PDPK2 and phosphorylates the $\mathrm{C}$ terminus of AKT at ser473, an obligatory event for full activation of AKT. Although the clinical importance of PDPK2 function in cancer is unknown, a recent study showed that mTORC2 is required for the development of prostate tumors that are induced by PTEN loss [87]. Therefore, a kinase inhibitor of mTOR that can target both mTORC1 and mTORC2 would be expected to block activation of the PI3K pathway more effectively than Rapamycin. Interestingly, however, the enhanced activity of these mTOR kinase inhibitors may not be due to mTORC2 inhibition. Instead, the enhanced activity seems to be due to more complete inhibition of mTORC1 activity, as indicated by measurements of mTORC1 dependent and Rapamycin independent 4EBP1 phosphorylation and cap dependent translation $[88,89]$. It should also be noted that several kinases in the PI3K pathway are client proteins for the heat shock protein 90 (HSP90) [90,91]. Therefore, compounds that inhibit HSP90, such as geldanamycin and its analogues, may have therapeutic effects mediated at least in part through inhibition of the PI3K pathway.

\section{Conclusion and Future Prospects}

Metabolism is involved directly or indirectly in essentially everything a cell does. There is mounting evidence for crosstalk between signaling pathways and metabolic control in every multicellular organism studied. Renewed interest in cancer metabolism has generated new hopes that a new class of therapeutic agents may finally appear on the stage for cancer therapy. There is still much to learn about how proliferating cell metabolism is regulated. Despite a long and rich history of research, the complex connection between metabolism and proliferation remains an exciting area of investigation. Indeed, new metabolic pathways have been discovered as recently and it is possible that additional pathways have yet to be described. Understanding this important aspect of biology is likely to have a major impact on our understanding of cell proliferation control and cancer and to develop new therapeutic strategies against cancer.

\section{References}

1. Luo J, Solimini NL, Elledge SJ (2009) Principles of cancer therapy: oncogene and non-oncogene addiction. Cell 136: 823-837.

2. Fritz V, Fajas L (2010) Metabolism and proliferation share common regulatory pathways in cancer cells. Oncogene 29: 4369-4377.

3. Marín-Hernández A, Rodríguez-Enríquez S, Vital-González PA, FloresRodríguez FL, Macías-Silva M, et al. (2006) Determining and understanding the control of glycolysis in fast-growth tumor cells. Flux control by an overexpressed but strongly product-inhibited hexokinase. FEBS J 273: 1975-1988.

4. Mathupala SP, Ko YH, Pedersen PL (2006) Hexokinase II: cancer's doubleedged sword acting as both facilitator and gatekeeper of malignancy when bound to mitochondria. Oncogene 25: 4777-4786.

5. Mathupala SP, Ko YH, Pedersen PL (2009) Hexokinase-2 bound to mitochondria: cancer's stygian link to the "Warburg Effect" and a pivotal target for effective therapy. Semin Cancer Biol 19: 17-24.

6. Bartrons R, Caro J (2007) Hypoxia, glucose metabolism and the Warburg's effect. J Bioenerg Biomembr 39: 223-229.

7. Atsumi T, Chesney J, Metz C, Leng L, Donnelly S, et al. (2002) High expression of inducible 6-phosphofructo-2-kinase/fructose-2,6-bisphosphatase (iPFK-2; PFKFB3) in human cancers. Cancer Res 62: 5881-5887.

8. Minchenko O, Opentanova I, Caro J (2003) Hypoxic regulation of the 6-phosphofructo-2-kinase/fructose-2- 6-bisphosphatase gene family (PFKFB 1-4) expression in vivo. FEBS Lett 554: 264-270.
9. Šmerc A, Sodja E, Legiša M (2011) Posttranslational Modification of 6-phosphofructo-1-kinase as an Important Feature of Cancer Metabolism. Plos One 6: 19645 .

10. Mazurek S, Boschek CB, Hugo F, Eigenbrodt E (2005) Pyruvate kinase type M2 and its role in tumor growth and spreading. Semin Cancer Biol 15: 300-308.

11. Christofk HR, Vander Heiden MG, Wu N, Asara JM, Cantley LC (2008) Pyruvate kinase M2 is a phosphotyrosine-binding protein. Nature 452: 181-186.

12. Marshall S, Bacote V, Traxinger RR (1991) Discovery of a metabolic pathway mediating glucose-induced desensitization of the glucose transport system. Role of hexosamine biosynthesis in the induction of insulin resistance. J Biol Chem 266: 4706-4712.

13. Christofk HR, Vander Heiden MG, Harris MH, Ramanathan A, Gerszten RE et al. (2008) The M2 splice isoform of pyruvate kinase is important for cancer metabolism and tumour growth. Nature 452: 230-233.

14. David CJ, Chen M, Assanah M, Canoll P, Manley JL (2009) HnRNP proteins controlled by c-Myc deregulate pyruvate kinase mRNA splicing in cancer Nature 463: 364-368.

15. Schneider J, Neu K, Grimm H, Velcovsky HG, Weisse G, et al. (2002) Tumor M2-pyruvate kinase in lung cancer patients: immunohistochemical detection and disease monitoring. Anticancer Res 22: 311-318.

16. Kim JW, Tchernyshyov I, Semenza GL, Dang CV (2006) HIF-1-mediated expression of pyruvate dehydrogenase kinase: a metabolic switch required for cellular adaptation to hypoxia. Cell Metab 3: 177-185.

17. Cairns RA, Papandreou I, Sutphin PD, Denko NC (2007) Metabolic targeting of hypoxia and HIF1 in solid tumors can enhance cytotoxic chemotherapy. Proc Natl Acad Sci U S A 104: 9445-9450.

18. Levine AJ, Puzio-Kuter AM (2010) The control of the metabolic switch in cancers by oncogenes and tumor suppressor genes. Science 330: 1340-1344.

19. Erickson JW, Cerione RA (2011) Glutaminase: a hot spot for regulation of cancer cell metabolism? Oncotarget 1: 734-740.

20. DeBerardinis RJ, Lum JJ, Hatzivassiliou G, Thompson CB (2008) The biology of cancer: metabolic reprogramming fuels cell growth and proliferation. Cell Metab 7: 11-19.

21. Hammoudi N, Ahmed KB, Garcia-Prieto C, Huang P (2011) Metabolic alterations in cancer cells and therapeutic implications. Chin J Cancer 30: 508525.

22. Hegymegi-Barakonyi B, Eros D, Szántai-Kis C, Breza N, Bánhegyi $P$, et al (2009) Tyrosine kinase inhibitors small molecular weight compounds inhibiting EGFR. Curr Opin Mol Ther 11: 308-321.

23. Sordella R, Bell DW, Haber DA, Settleman J (2004) Gefitinib-sensitizing EGFR mutations in lung cancer activate anti-apoptotic pathways. Science 305: 1163 1167.

24. Kuhajda FP (2008) AMP-activated protein kinase and human cancer: cancer metabolism revisited. Int J Obes 32: 36-41.

25. Shackelford DB, Shaw RJ (2009) The LKB1-AMPK pathway: metabolism and growth control in tumour suppression. Nature Rev Cancer 9: 563-575.

26. Hsu PP, Sabatini DM (2008) Cancer cell metabolism: Warburg and beyond. Cell 134: 703-707

27. Zhong H, De Marzo AM, Laughner E, Lim M, Hilton DA, et al. (1999) Overexpression of hypoxia-inducible factor 1 alpha in common human cancers and their metastases. Cancer Res 59: 5830-5835.

28. Medina RA, Owen GI (2002) Glucose transporters: expression, regulation and cancer. Biol Res 35: 9-26.

29. Wood IS, Trayhurn P (2003) Glucose transporters (GLUT and SGLT): expanded families of sugar transport proteins. Br J Nutr 89: 3-9.

30. Lewis BC, Prescott JE, Campbell SE, Shim H, Orlowski RZ, et al. (2000) Tumor induction by the c-Myc target genes $\mathrm{rcl}$ and lactate dehydrogenase A. Cancer Res 60: 6178-6183.

31. Kim JW, Gao P, Liu YC, Semenza GL, Dang CV (2007) Hypoxia-inducible factor 
Citation: Majeed R, Hamid A, Qurishi Y, Qazi AK, Hussain A, et al. (2012) Therapeutic Targeting of Cancer Cell Metabolism: Role of Metabolic Enzymes, Oncogenes and Tumor Suppressor Genes. J Cancer Sci Ther 4: 281-291. doi:10.4172/1948-5956.1000156

1 and dysregulated c-Myc cooperatively induce vascular endothelial growth factor and metabolic switches hexokinase 2 and pyruvate dehydrogenase kinase1. Mol Cell Biol 27: 7381-7393.

32. Osthus RC, Shim H, Kim S, Li Q, Reddy R, et al. (2000) Deregulation of glucose transporter 1 and glycolytic gene expression by c-Myc. J Biol Chem 275: 21797-21800

33. Kim J, Lee JH, lyer VR (2008) Global identification of Myc target genes reveals its direct role in mitochondrial biogenesis and its E-box usage in vivo. PLoS One 3: e1798.

34. Morrish F, Neretti N, Sedivy JM, Hockenbery DM (2008) The oncogene c-Myc coordinates regulation of metabolic networks to enable rapid cell cycle entry. Cell Cycle 7: 1054-1066.

35. Menendez JA, Colomer R, Lupu R (2005) Why does tumor-associated fatty acid synthase (oncogenic antigen-519) ignore dietary fatty acids? Med Hypotheses 64: 342-349

36. Yang YA, Han WF, Morin PJ, Chrest FJ, Pizer ES (2002) Activation of fatty acid synthesis during neoplastic transformation: role of mitogen-activated protein kinase and phosphatidylinositol 3-kinase. Exp Cell Res 279: 80-90.

37. Wong KK, Engelman JA, Cantley LC (2010) Targeting the PI3K signaling pathway in cancer. Curr Opin Genet Dev 20: 87-90.

38. Plas DR, Thompson CB (2005) Akt-dependent transformation: there is more to growth than just surviving. Oncogene 24: 7435-7442.

39. Manning BD, Cantley LC (2007) AKT/PKB signaling: navigating downstream. Cell 129: 1261-1274.

40. Elstrom RL, Bauer DE, Buzzai M, Karnauskas R, Harris MH, et al. (2004) AAkt stimulates aerobic glycolysis in cancer cells. Cancer Res 64: 3892-3899.

41. Barthel A, Okino ST, Liao J, Nakatani K, Li J, et al. (1999) RRegulation of GLUT1 gene transcription by the serine/threonine kinase Akt1. J Biol Chem 274: 20281-20286.

42. Gottlob K, Majewski N, Kennedy S, Kandel E, Robey RB, et al. (2001) Inhibition of early apoptotic events by Akt/PKB is dependent on the first committed step of glycolysis and mitochondrial hexokinase. Genes Dev 15: 1406-1418.

43. Di Chiro G, DeLaPaz RL, Brooks RA, Sokoloff L, Kornblith PL, et al. (1982) Glucose utilization of cerebral gliomas measured by [18F] fluorodeoxyglucose and positron emission tomography. Neurology 32: 1323-1329.

44. Porstmann T, Griffiths B, Chung YL, Delpuech O, Griffiths JR, et al. (2005) $\mathrm{PKB} /$ Akt induces transcription of enzymes involved in cholesterol and fatty acid biosynthesis via activation of SREBP. Oncogene 24: 6465- 6481.

45. Bauer DE, Hatzivassiliou G, Zhao F, Andreadis C, Thompson CB (2005) ATP citrate lyase is an important component of cell growth and transformation. Oncogene 24: 6314-6322.

46. Fang M, Shen Z, Huang S, Zhao L, Chen S, et al. (2010) The ER UDPase ENTPD5 promotes protein $\mathrm{N}$-glycosylation, the Warburg effect, and proliferation in the PTEN pathway. Cell 143: 711-724.

47. Cross DA, Alessi DR, Cohen P, Andjelkovich M, Hemmings BA (1995) Inhibition of glycogen synthase kinase- 3 by insulin mediated by protein kinase $B$. Nature 378: 785-789.

48. Robey RB, Hay N (2009) Is Akt the "Warburg kinase"?-Akt-energy metabolism interactions and oncogenesis. Semin Cancer Biol 19: 25-31.

49. Guertin DA, Sabatini DM (2007) Defining the role of mTOR in cancer. Cancer Cell 12: 9-22.

50. Semenza GL (2000) HIF-1: mediator of physiological and pathophysiological responses to hypoxia. J Appl Physiol 88: 1474-1480.

51. Robey IF, Lien AD, Welsh SJ, Baggett BK, Gillies RJ (2005) Hypoxia-inducible factor-1alpha and the glycolytic phenotype in tumors. Neoplasia 7: 324-330.

52. Minchenko O, Opentanova I, Caro J (2003) Hypoxic regulation of the 6-phosphofructo-2-kinase/fructose-2,6-bisphosphatase gene family (PFKFB-1-4) expression in vivo. FEBS Lett 554: 264-270.
53. Simon MC (2006) Coming up for air: HIF-1 and mitochondrial oxygen consumption. Cell Metab 3: 150-151.

54. Bensaad K, Tsuruta A, Selak MA, Vidal MN, Nakano K, et al. (2006) TIGAR, a p53-inducible regulator of glycolysis and apoptosis. Cell 126: 107-120.

55. Matoba S, Kang JG, Patino WD, Wragg A, Boehm M, et al. (2006) p53 regulates mitochondrial respiration. Science 312: 1650-1653.

56. Feng Z, Hu W, de Stanchina E, Teresky AK, Jin S, et al. (2007) The regulation of AMPK beta1, TSC2, and PTEN expression by p53: stress, cell and tissue specificity, and the role of these gene products in modulating the IGF-1-AKTmTOR pathways. Cancer Res 67: 3043-3053.

57. Feng Z, Zhang H, Levine AJ, Jin S (2005) The coordinate regulation of the p53 and mTOR pathways in cells. Proc Natl Acad Sci U S A 102: 8204-8209.

58. Li J, Yen C, Liaw D, Podsypanina K, Bose S, et al. (1997) PTEN, a putative protein tyrosine phosphatase gene mutated in human brain, breast, and prostate cancer. Science 275: 1943-1947.

59. Dali-Youcef N, Mataki C, Coste A, Messaddeq N, Giroud S, et al. (2007) Adipose tissue-specific inactivation of the retinoblastoma protein protects against diabesity because of increased energy expenditure. Proc Natl Acad Sci U S A 104: 10703-10708.

60. Tennant DA, Durán RV, Gottlieb E (2010) Targeting metabolic transformation for cancer therapy. Nat Rev Cancer 10: 267-277.

61. Ganapathy-Kanniappan S, Vali M, Kunjithapatham R, Buijs M, Syed LH, et al (2010) 3-bromopyruvate: a new targeted antiglycolytic agent and a promise for cancer therapy. Curr Pharm Biotechnol 11: 510-517.

62. Hammoudi N, Ahmed KB, Garcia-Prieto C, Huang P (2011) Metabolic alterations in cancer cells and therapeutic implications. Chin J Cancer 30: 508525 .

63. Clem B, Telang S, Clem A, Yalcin A, Meier J, et al. (2008) Small-molecule inhibition of 6-phosphofructo-2-kinase activity suppresses glycolytic flux and tumor growth. Mol Cancer Ther 7: 110-120.

64. Christofk HR, Vander Heiden MG, Wu N, Asara JM, Cantley LC (2008) Pyruvate kinase M2 is a phosphotyrosine-binding protein. Nature 452: 181-186.

65. Vander Heiden MG, Christofk HR, Schuman E, Subtelny AO, Sharfi $H$, et al. (2010) Identification of small molecule inhibitors of pyruvate kinase M2. Biochem Pharmacol 79: 1118-1124.

66. Shim H, Dolde C, Lewis BC, Wu CS, Dang G, et al. (1997) c-Myc transactivation of LDHA: implications for tumor metabolism and growth. Proc Natl Acad Sci U S A 94: 6658-6663.

67. Qing G, Skuli N, Mayes PA, Pawel B, Martinez D, et al. (2010) Combinatoria regulation of neuroblastoma tumor progression by $\mathrm{N}-\mathrm{Myc}$ and hypoxia inducible factor HIF-1alpha. Cancer Res 70: 10351-10361.

68. Le A, Cooper CR, Gouw AM, Dinavahi R, Maitra A, et al. (2010) Inhibition of lactate dehydrogenase $A$ induces oxidative stress and inhibits tumor progression. Proc Natl Acad Sci U S A 107: 2037-2042.

69. Thomas AA, Le Huerou Y, De Meese J, Gunawardana I, Kaplan T, et al. (2008) Synthesis, in vitro and in vivo activity of thiamine antagonist transketolase inhibitors. Bioorg Med Chem Lett 18: 2206-2210.

70. Wang JB, Erickson JW, Fuji R, Ramachandran S, Gao P, et al. (2010) Targeting mitochondrial glutaminase activity inhibits oncogenic transformation. Cancer Cell 18: 207-219.

71. Parsons DW, Jones S, Zhang X, Lin JC, Leary RJ, et al. (2008) An integrated genomic analysis of human glioblastoma multiforme. Science 321: 1807-1812.

72. Reitman ZJ, Yan H (2010) Isocitrate dehydrogenase 1 and 2 mutations in cancer: alterations at a crossroads of cellular metabolism. J Natl Cancer Inst 102: $932-941$.

73. Dang L, White DW, Gross S, Bennett BD, Bittinger MA, et al. (2009) Cancerassociated IDH1 mutations produce 2-hydroxyglutarate. Nature 462: 739-744.

74. Knight ZA, Shokat KM (2007) Chemically targeting the PI3K family. Biochem Soc Trans 35: 245-249. 
Citation: Majeed R, Hamid A, Qurishi Y, Qazi AK, Hussain A, et al. (2012) Therapeutic Targeting of Cancer Cell Metabolism: Role of Metabolic Enzymes, Oncogenes and Tumor Suppressor Genes. J Cancer Sci Ther 4: 281-291. doi:10.4172/1948-5956.1000156

75. Marone R, Cmiljanovic V, Giese B, Wymann MP (2008) Targeting phosphoinositide 3-kinase: moving towards therapy. Biochim Biophys Acta 1784: 159-185.

76. Knight ZA, Gonzalez B, Feldman ME, Zunder ER, Goldenberg DD, et al. (2006) A pharmacological map of the PI3-K family defines a role for p110alpha in insulin signaling. Cell 125: 733-747.

77. Fan QW, Knight ZA, Goldenberg DD, Yu W, Mostov KE, et al. (2006) A dua $\mathrm{PI} 3$ kinase/mTOR inhibitor reveals emergent efficacy in glioma. Cancer Cell 9: 341-349.

78. Maira SM, Stauffer F, Brueggen J, Furet P, Schnell C, et al. (2008) Identification and characterization of NVP-BEZ235, a new orally available dual phosphatidylinositol 3-kinase/mammalian target of rapamycin inhibitor with potent in vivo antitumor activity. Mol Cancer Ther 7: 1851-1863.

79. Garlich JR, De P, Dey N, Su JD, Peng X, et al. (2008) A vascular targeted pan phosphoinositide 3-kinase inhibitor prodrug, SF1126, with antitumor and antiangiogenic activity. Cancer Res 68: 206-215.

80. Hilgard P, Klenner T, Stekar J, Nössner G, Kutscher B, et al. (1997) D-21266, a new heterocyclic alkylphospholipid with antitumour activity. Eur J Cancer 33: 442-446.

81. Meuillet EJ, Ihle N, Baker AF, Gard JM, Stamper C, et al. (2004) In vivo molecular pharmacology and antitumor activity of the targeted Akt inhibitor PX316. Oncol Res 14: 513-527.

82. Gills JJ, Holbeck S, Hollingshead M, Hewitt SM, Kozikowski AP, et al. (2006) Spectrum of activity and molecular correlates of response to phosphatidylinositol ether lipid analogues, novel lipid-based inhibitors of Akt. Mol Cancer Ther 5 713-722.

83. Rhodes N, Heerding DA, Duckett DR, Eberwein DJ, Knick VB, et al. (2008)
Characterization of an Akt kinase inhibitor with potent pharmacodynamic and antitumor activity. Cancer Res 68: 2366-2374.

84. Vézina C, Kudelski A, Sehgal SN (1975) Rapamycin (AY-22,989), a new antifungal antibiotic. I. Taxonomy of the producing streptomycete and isolation of the active principle. J Antibiot (Tokyo) 28: 721-726.

85. Yatscoff RW, LeGatt DF, Kneteman NM (1993) Therapeutic monitoring of rapamycin: a new immunosuppressive drug. Ther Drug Monit 15: 478-482.

86. Faivre S, Kroemer G, Raymond E (2006) Current development of mTOR inhibitors as anticancer agents. Nature Rev Drug Discov 5: 671-688.

87. Guertin DA, Stevens DM, Saitoh M, Kinkel S, Crosby K, et al. (2009) mTOR complex 2 is required for the development of prostate cancer induced by Pten loss in mice. Cancer Cell 15: 148-159.

88. Feldman ME, Apsel B, Uotila A, Loewith R, Knight ZA, et al. (2009) Activesite inhibitors of mTOR target rapamycin-resistant outputs of mTORC1 and mTORC2. PLoS Biol 7: e38.

89. Thoreen CC, Kang SA, Chang JW, Liu Q, Zhang J, et al. (2009) An ATPcompetitive mammalian target of rapamycin inhibitor reveals rapamycinresistant functions of mTORC1. J Biol Chem 284: 8023-8032.

90. Fujita N, Sato S, Ishida A, Tsuruo T (2002) Involvement of Hsp90 in signaling and stability of 3-phosphoinositide-dependent kinase-1. J Biol Chem 277: 10346-10353.

91. Solit DB, Basso AD, Olshen AB, Scher HI, Rosen N (2003) Inhibition of hea shock protein 90 function down-regulates Akt kinase and sensitizes tumors to Taxol. Cancer Res 63: 2139-2144. 